\section{GERONTOLOGY} living longer

from a Correspondent

AT the international forum on the control of human ageing, held from September 2-4 at the Gottlieb Duttweiler Institute (The Green Meadow Foundation) in Switzerland, two different points of view became apparent-there were those participants who stated that research in life prolongation must continue and those who were appalled by the social and economic aftermath of such added years.

According to Professor F. Verzar (Institutes für Experimentelle Gerontologic, Basel), this century will be the century of the aged and progress will be made in social gerontology, medical geriatrics and experimental gerontology. A move to the right of the human taximeter clock giving a 10-20 per cent increase in life span may come and batteries of tests to measure ageing rate in the short term must be used. Calorie restriction remains the simplest method of prolonging life and if any active agent such as an antioxidant is used it should be capable of being introduced as late in life as possible to prolong active vigorous life without increasing dependent old age.

The search is now on for a substance which will turn off the process of ageing. Professor B. L. Strehler (University of California) suggested that if the human thermostat could be reprogrammed to $2^{\circ} \mathrm{C}$ or less life would be increased by 25 per cent.

According to Dr L. Robert (CNRS, Laboratoire de Biochimie du Tissu Conjonctif) immunological manifestations of age related disease are probably themselves part of a general generelated, differentiation-linked ageing mechanism. Orgel's (Proc. US Nat. Acad. Sci., 49, 517 ; 1963) theory of the inaccuracy of the protein synthesizing machinery of cells was supported by work with a strain of Neurospora (Dr C. M. Lewis, West London Hospital).

Professor I. Sobel (Florida State University) spoke on the employment problem of the over forty-fives. Older workers are already on average unemployed longer. Adding fifteen years to the life span would lead to a period of decline in earnings lasting for twentyfive to thirty years with serious consequential psychological upsets. Each 5 -year increase in life span would raise the labour force by about 5 per cent.

Professor W. F. Anderson (University of Glasgow) considered that prolongation of active human life without massive retraining programmes for the older worker and without encouragement to take up part-time employment associated with adequate medical and social resources for the existing elderly would be disastrous.
The pharmacological control of ageing was reviewed by $\mathrm{Dr} \mathrm{C}$. G. Kormendy (Bristol Laboratories, Syracuse). He suggested that the most promising substances should be subjected to laboratory studies. Most agents still seem to be too toxic.

Dr M. Goldsmith (Science Policy Foundation, London) stressed that vast socioeconomic implications must be considered before institutions of gerontology are established. Fortunately, gerontologists are unlikely to contribute to demographic pressure before the year 2000 and antioxidants, perhaps the least expensive agents, would have no significant effect until the early decades of the twenty-first century (Dr R. W. Prehoda, Toluca Lake Station, California). Dr R. D. Clarke (Prudential Insurance Company, London) thought that, by 1990 , therapies based on two or more ageing theories may extend the life span by 35 per cent. Any modest increase in contraception, abortion or sterilization would have greater impact on demographic pressures in the next thirty to forty years than the probable advances in gerontology.

In discussion, pleas were made for controlled studies now of the effect of certain endocrine substances, for example oestrogens in women, regarding their influence on the life pattern, and Dr J. Huet (International Center of Social Gerontology, Paris) made a forceful argument for an international institute of gerontology under Professor Verzar's administration.

The participants, although differing in the benefits of and means of prolongation of life, were unanimous in the need to plan now for larger numbers of old people. Multidisciplinary action should be taken by scientists, sociologists and physicians.

\title{
Drug Resistance in Cancer Chemotherapy
}

THE problem of the development of resistance to chemotherapy is one of the major difficulties in the path of successful treatment of disseminated cancer. A study of the mechanisms of resistance in man is extremely difficult for most cancers because remissions are uncommon and multiple biopsies of cancer material are not usually possible. A study of resistance to drugs in acute leukaemia, however, is feasible because multiple complete remissions are common and the blood and bone marrow can provide malignant cells at several stages during the development of the disease.

Drug resistance may develop because the agent is not taken up by the malignant cell or because enzymes are produced which catalyse its destruction either in the malignant cell itself or by normal tissues such as the liver. New metabolic pathways may be used to circumvent the metabolic block of the agent used. These types of resistance are likely to be specific for a single group of chemotherapeutic agents with similar modes of action. Another possible mechanism of resistance is less specific and depends on an alteration in the proliferation characteristics of the cancer cell. Such changes could result in an alteration in the effect of all drugs acting on cancer cells at the time of DNA synthesis which includes most anti-cancer chemotherapeutic agents. Resistance to a large number of drugs could therefore develop nonspecifically. There is growing evidence that all these mechanisms may be operative in man.

One example of resistance to a drug being modified by metabolic alterations within the cancer cell is provided by the treatment of acute lymphoblastic leukaemia using L-asparaginase. This agent is thought to act, at least in part, by depriving the malignant cells of the amino-acid L-asparagine. Resistance to L-asparaginase which develops during or following treatment has been associated with increased levels of asparagine synthetase activity within the leukaemic cell (S. M. Haskell et al., Cancer Res., 29, 974 ; 1969).

The response of acute leukaemia in man to treatment with the antimetabolite cytosine arabinoside has also shown a correlation with the rate of uptake of the drug in vitro and its subsequent activation by phosphorylation (M. Y. Chu and G. A. Fisher, Biochem. Pharmacol., 14. 333; 1965). Stewart and Burke report in next Wednesday's Nature New Biology that leukaemic cells from patients who respond to treatment contain six times less cytosine deaminase than is present in cells of those who do not respond. The concentration of this enzyme, which inactivates cytosine arabinoside, increases following a course of therapy and this is correlated with increased resistance to therapy.

Tests in vitro in man for predicting response to the initial treatment using different drugs are unfortunately unreliable-the tests pay no attention to an agent's absorption, detoxication, excretion, distribution and duration in the body. The mechanisms whereby cells can repair or circumvent damage by the agent may be very different in vivo. Nevertheless, in acute lcukaemia it may be possible to predict the development of resistance, following one course of treatment, to a particular drug. This could well be important in the management of patients relapsing with this discase. 